\title{
Charge density analysis of two proton transfer complexes: Understanding hydrogen bonding and determination of in-crystal dipole moments ${ }^{\dagger}$
}

\author{
REJI THOMAS ${ }^{\mathrm{a}}$, SHRINWANTU PAL ${ }^{\mathrm{a}}$, AYAN DATTA', MARIUSZ K MARCHEWKA', \\ HENRYK RATAJCZAK ${ }^{\mathrm{d}}$, SWAPAN K PATI ${ }^{\mathrm{b}, *}$ and G U KULKARNI ${ }^{\mathrm{a}, *}$ \\ ${ }^{\mathrm{a}}$ Chemistry and Physics of Materials Unit and ${ }^{\mathrm{b}}$ Theoretical Sciences Unit, \\ Jawaharlal Nehru Center for Advanced Scientific Research, Jakkur P.O., Bangalore 560064 \\ ${ }^{\mathrm{c}}$ Institute of Low Temperatures and Structure Research, Polish Akademy of Sciences, ul Okolna 2, \\ 50422 Wroclaw, Poland \\ ${ }^{\mathrm{d}}$ Faculty of Chemistry, University of Wroclaw 50-383 Wroclaw, Poland \\ e-mail: kulkarni@jncasr.ac.in
}

\begin{abstract}
An experimental charge density study has been carried out on proton-transfer complexes exhibiting nonlinear optical (NLO) properties-melaminium tartrate monohydrate and L-asparaginium picrate employing high-resolution X-ray diffraction at $100 \mathrm{~K}$. Both the complexes crystallize in non-centric space group $\mathrm{P} 2{ }_{1}$ and the structures exhibit interesting patterns of $\mathrm{N}-\mathrm{H} \ldots \mathrm{O}$ and $\mathrm{O}-\mathrm{H} \ldots \mathrm{O}$ hydrogen bonding. Experimental determination of the dipole moment $(\mu)$ for the asymmetric unit reveals that for both the crystals, there is a large cooperative enhancement in the crystalline $\mu$ arising essentially due to hydrogen bond mediated charge transfer between the melaminium ion and the L-tartrate in one case, between the Lasparaginium ion and the picrate in the other complex. We have additionally performed theoretical calculations at the density functional theory (DFT) level to understand the origin of enhancement of the dipole moments in the two systems.
\end{abstract}

Keywords. X-ray diffraction; experimental charge density; hydrogen bonding; dipole moment; $a b$ initio calculations.

\section{Introduction}

The last few decades have witnessed a tremendous interest in molecular materials and soft condensed matter. Such materials include organic solids, ${ }^{1-4}$ polymers, ${ }^{5}$ thin-films, ${ }^{6}$ micelles $^{7}$ and biomaterials ${ }^{8}$ which occupy a central-stage for both basic and applied research. These materials are being actively used for the design of smart devices such as organic light emitting diodes, ${ }^{9}$ hybrid organic-inorganic nanoporous materials ${ }^{10}$ important in gas-sensing, hydrogen storage and bio-mimetic applications. ${ }^{11}$

However, the optimization and fine-tuning of the properties of molecular materials is dually challenging. It calls for a sound understanding of the properties at the molecular level, which in turn demands an understanding of the intermolecular forces that glue the molecules in a material. In most systems, the in

\footnotetext{
${ }^{\dagger}$ Dedicated to Prof. C N R Rao on his 75th birthday

*For correspondence
}

termolecular interactions are the weak supramolecular forces involving hydrogen bonding ${ }^{12,13}$ and $\pi$ stacking. ${ }^{14}$ Thus, a basic understanding of the factors that control the intermolecular interactions in an aggregate is of fundamental interest for the proper design and fabrication of smart materials. ${ }^{15,16}$

An important class of organic materials is the nonlinear optically (NLO) active molecular crystals. ${ }^{17-19}$ A very stringent requirement for a material to exhibit non-zero second harmonic generation (SHG) is that the crystal has to exist in a non-centrosymmetric point group. In fact, most molecules (like paranitroaniline) which show very large SHG at the molecular scale due to charge transfer (CT) from the donor to the acceptor $\left(\mathrm{NH}_{2}\right.$ to $\left.\mathrm{NO}_{2}\right)$, crystallize in a centrosymmetric lattice due to predominating anti-parallel $\pi$-stacking between the aromatic rings as a consequence of dipolar interactions. ${ }^{20,21}$ However, weak intermolecular forces like H-bonding due to their directional nature can orient molecules in a head-totail manner thereby avoiding centrosymmetric packing and thus lead to enhanced SHG. ${ }^{22-25}$ 
For a proper understanding of the role of $\mathrm{H}$ bonding in controlling molecular packing and effectively the SHG responses in molecular crystals, we have performed an analysis of experimental charge density $(\rho(r))$ distribution in the crystal lattices of melaminium-L-tartrate monohydrarte (MELT) and L-asparaginium picrate (LASP) within the framework of Baders atoms-in-molecule (AIM) theory. ${ }^{26}$ The topological analysis of $\rho(r)$ based on AIM allows a quantitative description of bonds, non-bonding interactions, electronic structure and reactivity of a molecular system. ${ }^{27}$ The charge density $(\rho(r))$ analysis has been employed quite extensively to explore diverse aspects of a host of molecular systems. ${ }^{28} \mathrm{Re}-$ cent literature covers numerous experimental charge density studies on NLO active crystals. ${ }^{29}$ The advantage with the experimental charge density method is that it can provide complete estimation of the incrystal molecular properties. This becomes particularly important when the said property such as SHG arises only because of the crystal packing. The systems chosen in the present study are proton transfer complexes with known SHG activities of 1.2 $\left(\right.$ MELT $^{30}$ and 66 (LASP) ${ }^{31}$ times of KDP, respectively. Previous studies on NLO systems from this laboratory has shown that the non-centric crystal field can enhance the molecular dipole moment significantly. ${ }^{29 a}$ The present study shows that the $\mathrm{H}$ bonds mediate an extended charge-transfer with substantial increase in in-crystal dipole moments.

\section{Experimental}

Crystals of MELT and LASP were grown respectively from aqueous and acetone-aqueous solutions by slow evaporation at room temperature. High quality crystals were separated under an optical microscope and covered with epoxy. The crystal data were collected on a Siemens three circle diffractometer attached with a CCD area detector and a graphite monochromator for the $\operatorname{MoK} \alpha$ radiation $(50 \mathrm{kV}, 40 \mathrm{~mA})$. The crystals were cooled to $100 \mathrm{~K}$ on the diffractometer using a stream of cold nitrogen gas from a vertical nozzle and the temperature was maintained within $1 \mathrm{~K}$ throughout the data collection. The experimental details of the system are listed in table 1.

The unit cell parameters and the orientation matrix of the crystal were initially determined using $\sim 45$ reflections from 25 frames collected over a small $\omega$ scan of $12.5^{\circ}$ sliced at $0.5^{\circ}$ interval. A hemisphere of data of the reciprocal space with similar $2 \theta$ set- tings was collected. Data reduction was performed using the SAINT program ${ }^{32}$ (Bruker, 2002) matrix along the detector and the cell parameters were refined for every 40 frames on all the measured reflections. The experimental details for the system are listed in table 1. Absorption correction was applied on the data using the SADABS program ${ }^{33}$ (Bruker Nonius, 2004). The crystal structure was first determined with the low-resolution data up to $\sin (\theta / \lambda)=$ $0.56 \AA^{-1}$. The phase problem was solved by direct methods and the non-hydrogen atoms were refined anisotropically, by means of the full-matrix leastsquares procedure using the SHELXTL program. ${ }^{34}$ All the hydrogens were located using the difference Fourier method.

The charge density analysis was carried out on the basis of multipole expansion of the electron density centered at the nucleus of the atoms ${ }^{35}$ using XD package. ${ }^{36}$ The hydrogen atom positions were found using the difference Fourier method and were adjusted to average neutron values ${ }^{37}$ as commonly done during the multipole refinement. A high-order refinement of the data was performed using reflections with $\sin (\theta / \lambda) \geq 0.5 \AA^{-1}$ and $F_{o} \geq 5 \sigma$. All the hydrogens were held constant throughout the refinement along with their isotropic temperature factors. Multipolar refinement for the charge density analysis was carried out using the XDLSM routine of the XD package, and the details are given in table 1. The XDPROP routine was used to calculate the total electron density, $\rho(r)$, Laplacian, $\nabla^{2} \rho$ and the ellipticity, $\varepsilon$, at the bond critical points (BCPs) as well as the electrostatic potential, $\phi(r)$ profile. The deformation density maps have been plotted using the XDGRAPH routine. The electrostatic potential surface was plotted using MolIso program. ${ }^{38}$

\section{Results and discussion}

Figure 1 shows the asymmetric units of the molecular complexes MELT and LASP with atom labelling scheme. The asymmetric unit of MELT contains one diprotonated melaminium ion and one tartrate ion along with a molecule of water, whereas that of LASP consists of a picrate ion and a monoprotonated Lasparaginium ion. The refinement details of the complexes are given in the table 1 . Both the molecular complexes crystallize in a non-centric monoclinic space group $\mathrm{P} 2{ }_{1}$.

The molecular complex formed by melamine and tartaric acid displays a variety of hydrogen bonds 
Table 1. Refinement table for the complexes

\begin{tabular}{|c|c|c|}
\hline Compound & MELT & LASP \\
\hline Chemical formula & $\mathrm{C}_{7} \mathrm{H}_{14} \mathrm{~N}_{6} \mathrm{O}_{7}$ & $\mathrm{C}_{10} \mathrm{H}_{11} \mathrm{~N}_{5} \mathrm{O}_{10}$ \\
\hline Formula weight & $294 \cdot 24$ & $361 \cdot 24$ \\
\hline Cell setting & Monoclinic & Monoclinic \\
\hline Space group & $P 2_{1}$ & $P 2_{1}$ \\
\hline$a(\AA)$ & $4 \cdot 9727(1)$ & $10 \cdot 2441(4)$ \\
\hline$b(\AA)$ & $21.7273(1)$ & $5 \cdot 1147(2)$ \\
\hline$c(\AA)$ & $5 \cdot 5789(1)$ & $13 \cdot 0587(5)$ \\
\hline$\beta\left(^{\circ}\right)$ & $103 \cdot 580(2)$ & $94 \cdot 129(1)$ \\
\hline$\rho\left(\mathrm{Mg} / \mathrm{m}^{3}\right)$ & 1.668 & 1.758 \\
\hline$\mu, \mathrm{mm}^{-1}$ & $0 \cdot 148$ & $0 \cdot 160$ \\
\hline Cell volume $\left(\AA^{3}\right)$ & $585 \cdot 92(2)$ & $682 \cdot 44(5)$ \\
\hline Crystal size (mm) & $0.30 \times 0.20 \times 0.20$ & $0.25 \times 0.20 \times 0.20$ \\
\hline$Z$ & 2 & 2 \\
\hline$F(000)$ & 308 & 212 \\
\hline Diffractometer & $\begin{array}{l}\text { Siemens CCD } 3 \\
\text { circle diffractometer }\end{array}$ & $\begin{array}{l}\text { Siemens CCD } 3 \\
\text { circle diffractometer }\end{array}$ \\
\hline Radiation type & $\operatorname{MoK}_{\alpha}(0.71073 \AA)$ & $\operatorname{MoK}_{\alpha}(0.71073 \AA)$ \\
\hline Crystal-detector distance $(\mathrm{cm})$ & $5 \cdot 0$ & $5 \cdot 0$ \\
\hline No. of measured reflections & 9711 & 31898 \\
\hline No. of ind reflections & 7282 & 14978 \\
\hline No. of observed reflections & 5479 & 14968 \\
\hline Resolution $(\AA)$ & $0 \cdot 35$ & $0 \cdot 35$ \\
\hline$R_{\text {merge }}$ & $0 \cdot 0607$ & $0 \cdot 0354$ \\
\hline$R_{\text {int }}$ & $0 \cdot 0284$ & $0 \cdot 0297$ \\
\hline$R_{1}$ & $0 \cdot 0461$ & $0 \cdot 0360$ \\
\hline$w R 2$ & $0 \cdot 1106$ & 0.0977 \\
\hline$S$ & $1 \cdot 019$ & $1 \cdot 1070$ \\
\hline $\begin{array}{l}\text { No. of parameters refined } \\
\text { after multipole refinement }\end{array}$ & 237 & 270 \\
\hline Weighting scheme & $0 \cdot 0459,0 \cdot 0869$ & $0.0390,0.0765$ \\
\hline$R\{F\}$ & $0 \cdot 0309$ & $0 \cdot 0277$ \\
\hline$R\left\{F^{2}\right\}$ & $0 \cdot 0509$ & $0 \cdot 0382$ \\
\hline$S$ & $1 \cdot 180$ & $1 \cdot 1264$ \\
\hline$N_{\text {ref }} / N_{\mathrm{v}}$ & $11 \cdot 23$ & $35 \cdot 2212$ \\
\hline CCDC No. & 640612 & 640611 \\
\hline
\end{tabular}

within the three molecules of the asymmetric unit. The hydrogen bonds are either $\mathrm{O}-\mathrm{H} \cdots \mathrm{O}$ or $\mathrm{N}-\mathrm{H} \cdots \mathrm{O}$ type. The unique hydrogen-bonding patterns observed in the crystal structures are shown in figure 2. It is noteworthy that the water molecule in the crystal of melaminium L-tartrate (figure 2a) is located in between the two highly ionic species and engaged in a tetrahedral hydrogen-bonding environment via two $\mathrm{N}-\mathrm{H} \ldots \mathrm{O}(\mathrm{N} 2-\mathrm{H} 4 \ldots \mathrm{O} 1$ and $\mathrm{N} 3-\mathrm{H} 5 \ldots \mathrm{O} 1)$ and two $\mathrm{O}-\mathrm{H} \ldots \mathrm{O}(\mathrm{O} 1-\mathrm{H} 13 \ldots \mathrm{O} 4$ and $\mathrm{O} 1-\mathrm{H} 14 \ldots \mathrm{O} 6)$ interactions (see table 2). All the carboxylic acid and hydroxyl oxygen atoms of the tartaric acid participate in various $\mathrm{N}-\mathrm{H} \ldots \mathrm{O}$ and $\mathrm{O}-\mathrm{H} \ldots \mathrm{O}$ interactions and play an important role in directing the crystal structure. The interaction between the melaminium residue and tartrate includes two pairs of $\mathrm{N}-\mathrm{H} \ldots \mathrm{O}$ hydrogen bonds, $(\mathrm{N} 5-\mathrm{H} 8 \ldots \mathrm{O} 2$ and $\mathrm{N} 3-\mathrm{H} 6 \ldots \mathrm{O} 3$ as well as $\mathrm{N} 2-\mathrm{H} 3 \ldots \mathrm{O} 6$ and $\mathrm{N} 6-\mathrm{H} 7 \ldots \mathrm{O} 7)$ which are formed between the tartrate oxygens and hydrogens from melamine. In addition, the tartrate ion forms an internal $\mathrm{O}-\mathrm{H} \ldots \mathrm{O}$ interaction $(\mathrm{O} 5-\mathrm{H} 12 \ldots \mathrm{O} 6$, not shown), involving the carboxylate oxygen and one of the hydroxyl groups.

The molecular complex of L-asparagine with picric acid also shows interesting hydrogen bonding pattern (figure $2 \mathrm{~b}$ ) and these interactions are mainly $\mathrm{N}-\mathrm{H} \ldots \mathrm{O}$ type. These $\mathrm{N}-\mathrm{H} \ldots \mathrm{O}$ interactions are originated from either the amide or amino group of the $\mathrm{L}$-asparaginium ion. The $\mathrm{N}-\mathrm{H}$... O interactions are in the range of $1.790-2.360 \AA$ with bond angles $170 \cdot 8-135 \cdot 3^{\circ}$ (see table 2 ). In addition to this, there exists a strong $\mathrm{O}-\mathrm{H} \ldots \mathrm{O}(\mathrm{O} 10-\mathrm{H} 11 \ldots \mathrm{O} 1)$ hydrogen bond, which is formed by the phenolate oxygen of picrate and the carboxylic group of the L-asparagine. 
Table 2. Hydrogen bond critical point parameters.

\begin{tabular}{|c|c|c|c|c|c|c|}
\hline Complexes & Bonds & H...A $(\AA)$ & $\mathrm{D} \ldots \mathrm{A}(\AA)$ & $\mathrm{D}-\mathrm{H} \ldots \mathrm{A}\left({ }^{\circ}\right)$ & $\rho\left(\AA^{-3}\right)$ & $\nabla^{2} \rho\left(\mathrm{e} \AA^{-5}\right)$ \\
\hline \multirow[t]{11}{*}{ MELT } & $\mathrm{N}(1)-\mathrm{H}(1) \ldots \mathrm{O}(5)$ & $1 \cdot 890(2)$ & $2 \cdot 887(1)$ & $168 \cdot 80$ & $0 \cdot 11(5)$ & $2 \cdot 95(2)$ \\
\hline & $\mathrm{N}(1)-\mathrm{H}(2) \ldots \mathrm{O}(3)$ & $1 \cdot 920(1)$ & $2 \cdot 929(2)$ & $178 \cdot 82$ & $0 \cdot 13(5)$ & $2 \cdot 96(2)$ \\
\hline & $\mathrm{N}(2)-\mathrm{H}(3) \ldots \mathrm{O}(6)$ & $1 \cdot 880(3)$ & $2 \cdot 882(1)$ & $171 \cdot 42$ & $0 \cdot 13(6)$ & $3 \cdot 13(4)$ \\
\hline & $\mathrm{N}(2)-\mathrm{H}(4) \ldots \mathrm{O}(1)$ & $1 \cdot 843(3)$ & $2 \cdot 835(2)$ & $166 \cdot 90$ & $0 \cdot 27(5)$ & $3 \cdot 53(3)$ \\
\hline & $\mathrm{N}(3)-\mathrm{H}(5) \ldots \mathrm{O}(1)$ & $1 \cdot 888(5)$ & $2 \cdot 889(1)$ & $171 \cdot 38$ & $0 \cdot 15(5)$ & $3 \cdot 08(3)$ \\
\hline & $\mathrm{N}(3)-\mathrm{H}(6) \ldots \mathrm{O}(3)$ & $1.835(4)$ & $2 \cdot 840(1)$ & $174 \cdot 08$ & $0 \cdot 24(5)$ & $3 \cdot 16(3)$ \\
\hline & $\mathrm{N}(6)-\mathrm{H}(7) \ldots \mathrm{O}(7)$ & $1 \cdot 578(3)$ & $2 \cdot 587(1)$ & $164 \cdot 26$ & $0 \cdot 40(1)$ & $4 \cdot 1(2)$ \\
\hline & $\mathrm{N}(5)-\mathrm{H}(8) \ldots \mathrm{O}(2)$ & $1 \cdot 567(1)$ & $2 \cdot 592(1)$ & $170 \cdot 88$ & $0 \cdot 50(9)$ & $4 \cdot 31(1)$ \\
\hline & $\mathrm{O}(5)-\mathrm{H}(12) \ldots \mathrm{O}(6)$ & $1 \cdot 813(3)$ & $2 \cdot 751(1)$ & $162 \cdot 88$ & $0 \cdot 10(5)$ & $3 \cdot 5(3)$ \\
\hline & $\mathrm{O}(1)-\mathrm{H}(13) \ldots \mathrm{O}(4)$ & $2 \cdot 121(3)$ & $2 \cdot 992(1)$ & $142 \cdot 61$ & $0 \cdot 03(2)$ & $0 \cdot 86(1)$ \\
\hline & $\mathrm{O}(1)-\mathrm{H}(14) \ldots \mathrm{O}(6)$ & $1 \cdot 765(2)$ & $2 \cdot 774(1)$ & $172 \cdot 54$ & $0 \cdot 18(7)$ & $4 \cdot 06(6)$ \\
\hline \multirow[t]{8}{*}{ LASP } & $\mathrm{N}(4)-\mathrm{H}(3) \ldots \mathrm{O}(1)$ & $2 \cdot 295(2)$ & $3 \cdot 094(2)$ & $135 \cdot 28$ & $0 \cdot 08(1)$ & $1 \cdot 14(3)$ \\
\hline & $\mathrm{N}(4)-\mathrm{H}(3) \ldots \mathrm{O}(2)$ & $2 \cdot 359(3)$ & $3 \cdot 155(2)$ & $135 \cdot 05$ & $0 \cdot 07(1)$ & $1 \cdot 05(4)$ \\
\hline & $\mathrm{N}(4)-\mathrm{H}(4) \ldots \mathrm{O}(2)$ & $2 \cdot 132(3)$ & $3 \cdot 072(2)$ & $154 \cdot 19$ & $0 \cdot 07(1)$ & $1.05(4)$ \\
\hline & $\mathrm{N}(5)-\mathrm{H}(7) \ldots \mathrm{O}(7)$ & $2 \cdot 138(2)$ & $3 \cdot 069(2)$ & $148 \cdot 83$ & $0 \cdot 04(2)$ & $1 \cdot 01(3)$ \\
\hline & $\mathrm{N}(5)-\mathrm{H}(8) \ldots \mathrm{O}(9)$ & $1.790(2)$ & $2 \cdot 814(2)$ & $170 \cdot 81$ & $0 \cdot 16(4)$ & $3 \cdot 65(3)$ \\
\hline & $\mathrm{N}(5)-\mathrm{H}(9) \ldots \mathrm{O}(8)$ & $2 \cdot 012(3)$ & $2 \cdot 867(2)$ & $138 \cdot 39$ & $0 \cdot 07(2)$ & $1 \cdot 97(4)$ \\
\hline & $\mathrm{O}(10)-\mathrm{H}(11) \ldots \mathrm{O}(1)$ & $1 \cdot 573(3)$ & $2 \cdot 561(2)$ & $163 \cdot 16$ & $0 \cdot 30(6)$ & $7 \cdot 19(8)$ \\
\hline & $\mathrm{C}(9)-\mathrm{H}(6) \ldots \mathrm{O}(8)$ & $2 \cdot 494(2)$ & $3 \cdot 225(2)$ & $123 \cdot 31$ & $0.05(8)$ & $0.77(4)$ \\
\hline
\end{tabular}

(a)
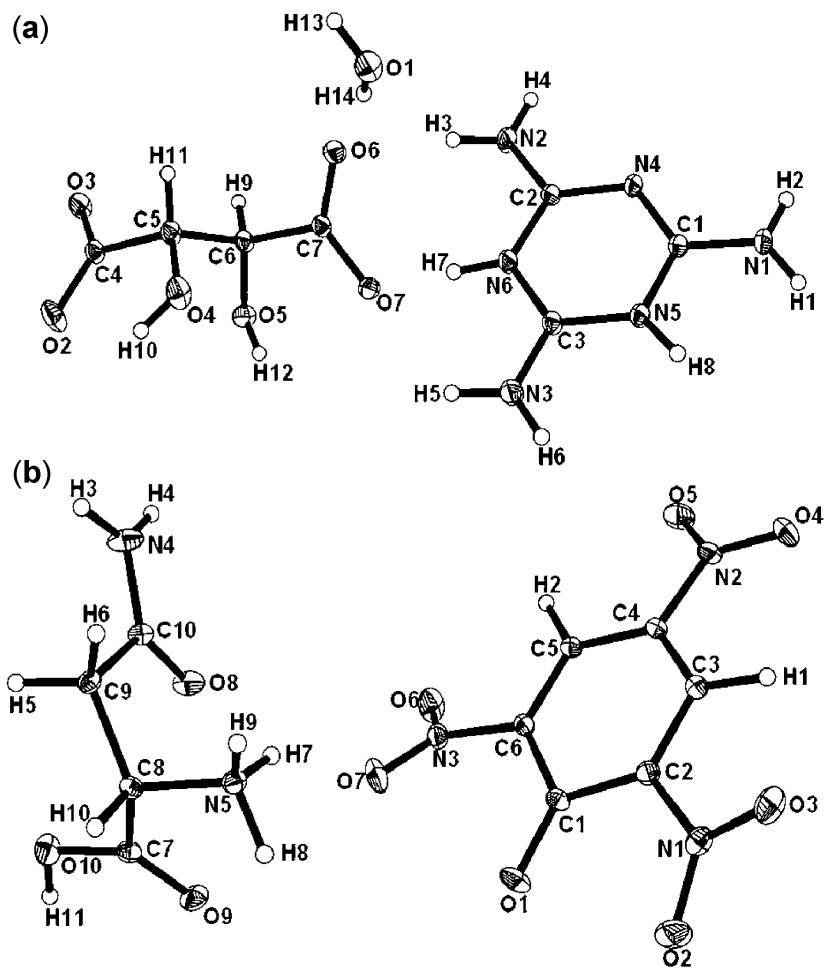

Figure 1. ORTEP representation of the molecular complexes (a) melaminium tartrate monohydrate (MELT), (b) L-asparaginium picrate (LASP). Displacement ellipsoids are drawn at a $50 \%$ probability level.

A $\mathrm{C}-\mathrm{H} \ldots \mathrm{O}$ interaction $(\mathrm{C} 9-\mathrm{H} 6 \ldots \mathrm{O} 8)$ is also formed between two asparginium ions.

\subsection{Analysis of experimental charge density}

In order to correlate the structure and charge density distribution to property, we have carried out a detailed charge density analysis on both the molecular complexes of MELT and LASP crystals and obtained density and Laplacian (see Supplementary information) as well as electrostatic potential iso surfaces. In MELT, the bond critical point parameters of melaminium ion indicate the variation in charge delocalization on protonation of the ring nitrogen (see Supplementary table 3). We compare the bond critical point properties of the protonated melamine ring with that of the previously reported melamine molecule. ${ }^{39}$ The density at the bond critical point is slightly decreased and it is in the range of 2.22(7) to $2.59(6) \mathrm{e}^{-3}$ whereas in the pure melamine ring, the values are in the range, 2.4(2) to 2.62(2) $\mathrm{e}^{-3}$ (see Supplementary table 3). The Laplacian of the density shows larger variations. These values are in the range, $-18 \cdot 2(2)$ to $-32 \cdot 0(3) \mathrm{e}^{-5}$ and $-21 \cdot 1(2)$ to $-25 \cdot 5(3) \mathrm{e} \AA^{-5}$ for protonated and non-protonated rings respectively. The variation of the Laplacian is interesting in the case of the protonated ring, where the values are higher for the bonds, which involve the protonated nitrogen atoms. The density and Laplacian in the bonding regions of the carboxylate ion of the tartrate are in the ranges, $3 \cdot 08(8)-2 \cdot 65(9)$ e $\AA^{-3}$ and $-51.9(4)--17 \cdot 10(2) \mathrm{e}^{-5}$ respectively. In the case of LASP (see Supplementary table 4), we see 
that the density and Laplacian for the $\mathrm{C}-\mathrm{C}$ bonds in picrate anion are typical of an aromatic system, $1 \cdot 87(3)$ to $2 \cdot 34(4) \mathrm{e}^{-3}$ and $-15 \cdot 5(1)$ to $-20 \cdot 0(1) \mathrm{e} \AA^{-5}$, respectively and that for the $\mathrm{C}-\mathrm{N}$ bonds are in the range, $1.79(4)$ to $1.93(4) \mathrm{e}^{-3}$ and $-11.8(1)$ to 13.0(1) e $\AA^{-5}$. In L-asparaginium ion, the $\mathrm{C}-\mathrm{C}$ charge density and Laplacian values indicate the single bond nature of the bonds. The density values for the two carboxylic acid $\mathrm{C}-\mathrm{O}$ bonds are 2.93(5) and 2.40(4) $\mathrm{e} \AA^{-3}$ with the corresponding Laplacian values of $-33 \cdot 8(3)$ and $-26 \cdot 7(2) \mathrm{e}^{-5}$. The proton transfer from the picric acid gives rise to a carboxylic acid group (in place of a carbolylate ion) resulting in two unequal $\mathrm{C}-\mathrm{O}$ bonds. The density and Laplacian for the $\mathrm{C}(8)-\mathrm{N}(5)$ are $1.65(3) \mathrm{e} \AA^{-3}$ and $-8.4(1) \mathrm{e}^{-5}$ respectively. This indicates a decrease in the bond strength due to the ionic nature of the nitrogen atom.

We have also carried out a charge density analysis of the various hydrogen bonds in the crystal struc-

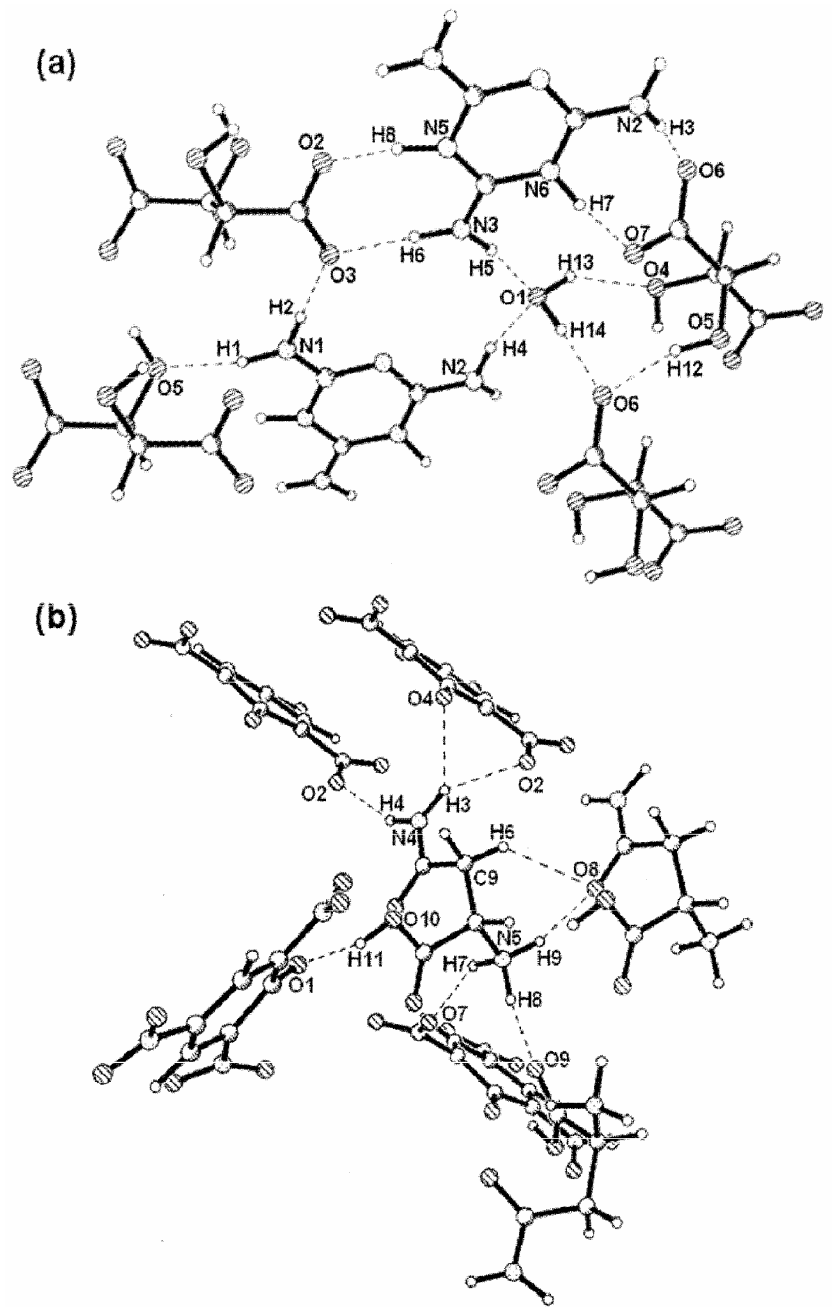

Figure 2. Unique set of hydrogen bonds observed in the molecular complexes (a) MELT, (b) LASP. ture. The details of the density distribution with respective hydrogen bond geometry are given in table 2. It is worthwhile to understand the variation in density and Laplacian of the density with respect to the hydrogen bond strength, measured in terms of the H...A distance and the D-H...A angle. For the $\mathrm{N}-\mathrm{H} \cdots \mathrm{O}$ interactions in MELT crystals, the density and Laplacian values fall in the range of $0 \cdot 11(5)$ to $0.50(9) \mathrm{e}^{-3}$ and $2.95(2)$ to $4.31(1) \mathrm{e}^{-5}$ respectively. These values are in good agreement with the standard values ${ }^{39}$ expected for a strong $\mathrm{N}-\mathrm{H} \cdots \mathrm{O}$ hydrogen bond, with short $\mathrm{H} \cdots \mathrm{A}$ distances and angles beyond $170^{\circ}$ (see table 2). Conversely, the $\mathrm{O}-\mathrm{H} \ldots \mathrm{O}$ interactions in MELT carry a density and Lapacian values in the range of $0 \cdot 10(5)$ to $0 \cdot 18(7) \mathrm{e}^{-3}$ and $0 \cdot 86(1)$ to $4 \cdot 06(6) \mathrm{e}^{-5}$ showing that these interactions are moderately strong. It is clear that in this complex, the dominant interactions are through $\mathrm{N}-$ $\mathrm{H}$... O hydrogen bonds. We have also carried out the charge density analysis on the hydrogen bonding interaction in LASP (see table 2). The density and Laplacian for $\mathrm{N}-\mathrm{H}$... O hydrogen bonds in these systems are in the range $0 \cdot 04(2)$ to $0 \cdot 16(4) \mathrm{e}^{-3}$ and $1.01(3)$ to $3.65(3) \mathrm{e} \AA^{-5}$, somewhat low for a standard $\mathrm{N}-\mathrm{H} \ldots \mathrm{O}$ interaction. On the other hand, the values for the $\mathrm{O}-\mathrm{H}$... O interaction $\left(0 \cdot 30(6) \mathrm{e}^{-3}\right.$ and 7.19(8) $\mathrm{e} \AA^{-5}$ ) indicate that this corresponds to a strong interaction. In general, it is clear from table 2 that the hydrogen bonding interactions in LASP are comparatively weaker than those existing in MELT.

A useful application of the multipole model of the electron density is the ability to derive the molecular electrostatic potential for an isolated molecule in the crystalline environment, and hence to evaluate contributions of electrostatics to intermolecular interactions and on molecular property. ${ }^{40}$ Figures $3 a$ and $b$ show the electrostatic potential on the iso electron density surface at $\rho=0.5 \mathrm{e} \AA^{-3}$, in MELT and LASP respectively. The maps indicate the donor acceptor sites for hydrogen bonding present in both the proton-transfer complexes. It is interesting to note that in MELT (figure 3a) the L-tartrate carries most of the negative potential (red) whereas the surface over melaminium ion is with positive values (green and blue) clearly implying proton transfer between these molecules. In the perspective given in figure $3 \mathrm{a}$, the water molecule is seen carrying negative lobes (red) corresponding to the lone-pair. A similar observation can be made in the LASP where the negative potential surface (red) is over the picrate ion and positive surface (green and blue) on the L-asparaginium 
ion, hence the charge transfer (see figure 3b), this case being more vivid than for MELT in figure $3 \mathrm{a}$. Thus LASP presents a case of proton transfer where the charge transfer is almost complete with the prevailing hydrogen bonds being relatively weaker.

The dipole moments of the asymmetric units have been estimated with respect to the center of mass as the origin, although the values themselves are independent of the choice of origin as the asymmetric unit as a whole is neutral. ${ }^{41}$ The values for MELT and LASP are 22.1(5) and 40.6(7) D respectively (see figures $3 \mathrm{c}$ and $\mathrm{d}$ respectively). The charge separation in LASP being distinct, a high value of dipole moment is rather expected. The dipole moments of the various molecular partners within the two asymmetric units are ill-defined quantities as they are charged species (except water molecule). It is interesting to note that the dipole moment in water molecule in the former is doubled in this ionic crystalline environment (gas-phase dipole-moment of water $=1 \cdot 84 \mathrm{D}){ }^{42}$ (a)

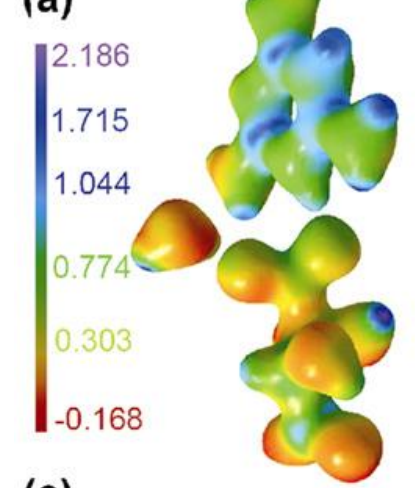

(c)

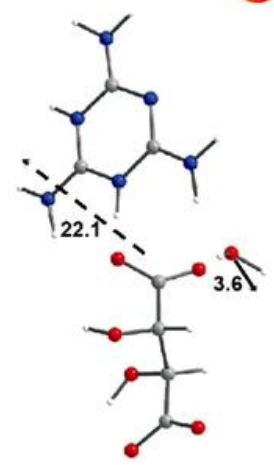

(b)

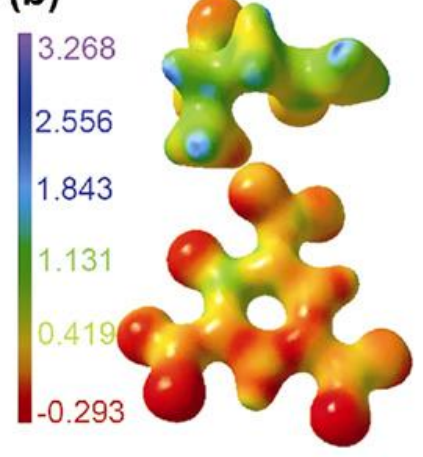

(d)

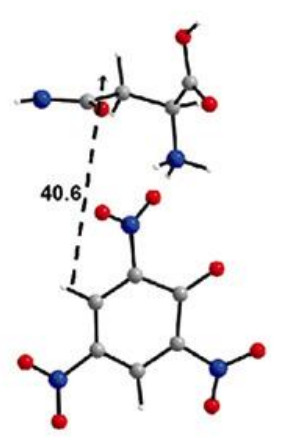

Figure 3. Experimental electrostatic potential of (a) MELT, (b) LASP on the $0.5 \mathrm{e}^{-3}$ isodensity surface. A colour gradient is applied to show the change from electronegative (towards red) to electropositive (towards blue) regions. The dipole moments of the asymmetric unit are shown: (c) melaminium tartrate monohydrate and (d) aspraginium picrate. Note the dipole moment of water, $(3.6 \mathrm{D})$ in $(\mathbf{c})$.
Coppens $e t a l^{43}$ have reported an enhancement in the water dipole-moment in non-centro symmetric crystal field. Previous theoretical calculations by Batista et $a l^{44}$ in hexagonal ice structure have shown that the dipole-moment of water can reach as high as 3.09 D. The present study reports the experimental value of $3 \cdot 6 \mathrm{D}$.

\subsection{Theoretical calculations}

In order to understand the origin of such high values of the in-crystal dipole moments of the molecular complexes, we have performed ab-initio calculations using the ADF2006.01 package, ${ }^{45}$ at GGA-PW91 level with TZP quality basis set for all atoms, involving all electrons. Note that, the positions for the hydrogen atoms can not be taken directly from the experimental data but are optimized, while the positions for the heavier atoms are used as determined from the crystal structure. Consequently, there are some differences between the computed and the experimental results. The main difference is that for MELT, the proton is situated almost midway between the oxygen of tartrate and nitrogen of melaminium ions, suggesting symmetric single well hydrogen bonding potential. The plots of the highest occupied molecular orbital (HOMO) and the lowest unoccupied molecular orbitals (LUMO) for both the neutral asymmetric units are shown in figure 4 , where the charge-transfer between the molecular partners is clearly evident. The total SCF electron density plots (see supplementary information figure S4) also show charge transfer from respective fragments in both MELT and LASP.

We present below, the computed dipole moments of the neutral asymmetric units in relation to the dipole moments of the molecular partners, treating the latter with no charge localization. ${ }^{46}$ From the individual components of the dipole-moment vectors, the average dipole-moment is calculated as:

$$
\bar{\mu}=\sqrt{\mu_{x}^{2}+\mu_{y}^{2}+\mu_{z}^{2}} .
$$

For MELT, the asymmetric unit has a dipole moment of $38.39 \mathrm{D}$, aligned nearly along its long axis. When we assume the fragment charges to be not localized, the tartrate (0) and melaminium (0) components exhibit dipole moments of $2.86 \mathrm{D}$ and $0.94 \mathrm{D}$ respectively, typically like the gas phase values for neutral molecules. Although the computed dipole moment of the asymmetric unit is deviated with respect to the experimental value $(22 \cdot 1 \mathrm{D})$, the large enhance- 
ment compared to the classical vector some of the neutral partners is quite apparent. This is also true of LASP (27.01 D) with picrate $(0)$ and L-asparaginium (0) having dipole moments of 1.01 and $2.92 \mathrm{D}$ respectively.

The extent of charge-transfer and the prevailing hydrogen bonds seem to govern the value of the dipole moment of the asymmetric unit. The molecular partners with no charge localization carry small dipole moments and are comparable in both the cases (0.9-3D). The high values of the asymmetric unit dipole moment encountered (both in experiment and theory) originate from the internal charge-transfer between the partners in both the complexes. The hydrogen bonding between the partners appears to have a counter effect; the stronger the bonding, lesser the charge-transfer and lower the total dipole moment, as evident from the experimental findings. However, the deviation with respect to the computed values is primarily due to the additional $\mathrm{H}$-bonding interactions that exist between the neighbouring asymmet-

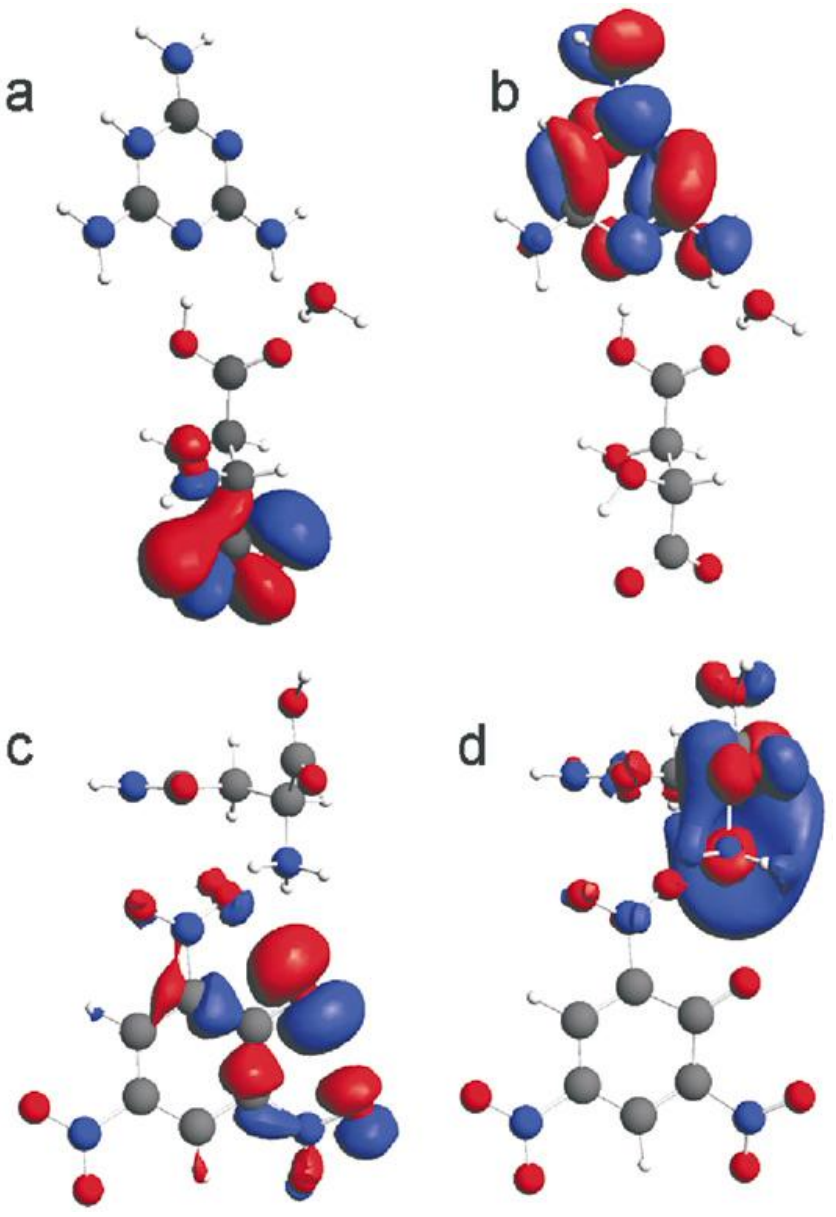

Figure 4. Frontier orbitals of MELT (HOMO a, LUMO b) and LASP (HOMO c, LUMO d). ric units, which are not considered within our gasphase calculations on single asymmetric units. Nevertheless even for a single-asymmetric unit, the charge-transfer interactions within the molecular partners enhance the dipole moment to a large extent. The main point is that charge transfer can be induced and controlled through the hydrogen bonding and other weak interactions, causing local charge redistribution which in turn increases the macroscopic polarization response by many fold qualifying the crystal for second harmonic generation.

\section{Conclusions}

Based on our joint experimental and theoretical studies on the crystals of melaminium-tartrate monohydrate and L-asparaginium-picrate molecular complexes, we have determined the charge-transfer characteristics of the hydrogen bonding interactions between the molecules. The origin of the large enhancement in the crystal dipole moments in both the crystals is attributed to the presence of charge transfer interactions between the constituent molecules, facilitated through the hydrogen bonds. Interestingly, the dipole moment of the water of crystallization in melaminium-tartrate monohydrate determined to be twice as large as that in the gas-phase, which is again a consequence of the charge transfer interactions within the monomer that create a local charging environment for the water molecule. Our work provides a comprehensive understanding of the intermolecular forces prevalent in these important nonlinear optical materials. Supplementary information can be obtained from the author through e-mail.

\section{Acknowledgements}

SKP and GUK thank Department of Science and Technology (DST), Council of Scientific and Industrial Research (CSIR), Defence Research Development Organization (DRDO), Government of India for research grants. They are thankful to Prof. C N R Rao for his encouragement. MKM and HR thank the Polish Ministry of Science and Higher Education for financial support (Project No. 3T09A 121 28).

\section{References}

1. Batail P 2004 Chem. Rev. 1044887

2. Pal S K, Itkis M E, Reed R W, Oakley R T, Cordes A W, Tham F S, Siegrist T and Haddon R C $2004 \mathrm{~J}$. Am. Chem. Soc. 1261478 
3. Zelichenok A, Burtman V, Zenou N, Yitzchaik S, Bella S D, Meshulam G and Kotler Z 1999 J. Phys. Chem. B103 8702

4. Nakatani K and Delaire J A 1997 Chem. Mater. 92682

5. (a) Tessler N, Harrison N T and R H Friend 1998 Adv. Mater. 10 64; (b) Ahlheim M and Lehr F 1994 Macromol. Chem. Phy. 195361

6. Lukas S, Pascal D, Mila B, Kirsten L, Mathieu H J, Manfred M and Horst V 1999 Angew. Chem. Int. Ed. 38696

7. Nagano S, Matsushita Y, Ohnuma Y, Shinma S and Seki T 2006 Langmuir 225233

8. Yan H, Park S H, Finkelstein G, Reif J H and LaBean T H 2003 Science 3011882

9. Mori T, Tsuge $\mathrm{H}$ and Mizutani T 1999 J. Phys. D: Appl. Phys. 32 L65

10. Rao C N R, Natarajan S and Vaidhyanathan R 2004 Angew. Chem. Int. Ed. 431466

11. Hecht S and Frechet J M J Angew. 2001 Chem. Int. Ed. 4074

12. Steiner T 2002 Angew. Chem. Int. Ed. 4148

13. Desiraju G R 1995 Angew. Chem. Int. Ed. 342311

14. Kaafarani B R, Wex B, Oliver A G, Bauer J A K and Neckers D C 2003 Acta Cryst. E59 227

15. Ellena J, Goeta A E, Howard J A K and Punte G 2001 J. Phys. Chem. A105 8696

16. Choi H S, Huh K M, Ooya T and N Yui $2003 \mathrm{~J}$. Am. Chem. Soc. 1256350

17. Zhao H, Li Y H, Wang X S, Qu Z R, Wang L Z, Xiong R G, Abrahams B F and Xue Z 2004 Chem. Eur. J. 102386.

18. Bogani L, Cavigli L, Bernot K, Sessoli R, Gurioli M and Gatteschi D 2006 J. Mater. Chem. 262587

19. Ravi M, Gangopadhyay P, Rao D N, Cohen S, Agranat I and Radhakrishnan T P 1998 Chem. Mater. 102371

20. Abrahams S C and Robertson J M 1948 Acta Cryst. 1252

21. Donhue J and Trueblood K N 1956 Acta Cryst. 9960

22. Datta A and Pati S K 2006 Chem. Soc. Rev. 35 1305; Datta A and Pati S K 2005 Chem. Eur. J. 114961

23. Datta A Davis D Sreekumar K and Pati S K $2005 \mathrm{~J}$. Phys. Chem. A109 4112

24. Datta A and Pati S K 2004 J. Phys. Chem. A108 320

25. Datta A and Pati S K 2003 J. Chem. Phys. 1188420

26. Bader R F W 1990 Atoms in molecules a quantum theory (Oxford: Clanderon Press)

27. Koritsanzsky T and Coppens P 2001 Chem. Rev. 101 1583

28. (a) Koritsanszky T, Flaig R, Zobel D, Krane H-G, Morgenroth W and Luger P 1998 Science 279 356; (b) Vokov A V, Koritsanszky T and Coppens P 2004 J. Phys. Chem. A108 4283; (c) Mallinson P R, Smith G T, Wilson C C, Grech E and Wozniak K $2003 \mathrm{~J}$. Am. Chem. Soc. 125 4259; (d) Wozniak K, Mallinson P R, Wilson C C, Hovestreydt E and Grech E J 2002 Phys. Chem. A106 6897; (e) Wagner A, Flaig R, Dittrich B, Schmidt H, Koritsanszky T and Luger P 2004 Chem. Eur. J. 10 2977; (f) Dittrich B, Koritsanszky T and Luger P 2004 Angew. Chem. Int. Ed. 43 2718; (g) Ranganathan A, Kulkarni G U and Rao C N R 2003 J. Phys. Chem. A107 6073
29. (a) Gopalan R S, Kulkarni G U and Rao C N R 2000 Chemphyschem 1 127; (b) Cole J M, Copley R C B, McIntyre G J and Howard J A K 2002 Phys. Rev. B65 125107; (c) Cole J M 2003 Phil. Trans. R. Soc. Lond. A361 2751; (d) Cole J M, Goeta A E, Howard J A K and McIntyre G J 2002 Acta Cryst. B58 690; (e) Spackman M A, Munshi P and Dittrich B 2007 Chemphyschem $\mathbf{8} 2022$

30. Marchewka M K, Baran J Pietraszko A Haznar A, Debrus S and Ratajczak H 2003 Sol. Stat. Sci. 5509

31. Srinivasan P, Kanagasekaran T, Gopalakrishnan R, Bhagavannarayana G and Ramasamy P 2006 Cryst. Growth. Des. 61663

32. Bruker AXS, SAINT Software Reference Manual v. 6.23, Madison, WI, 2002

33. Blessing R 1995 Acta Cryst. A51 33

34. Sheldrick G M 1990 SHELXS-97: Crystal Structure Solution, Version 97-1, Institut Anorg. Chemie, University of Gottingen, Germany

35. Hansen N K and Coppens P 1978 Acta. Cryst. A34 909

36. Koritsanszky T S, Howard S, Macchi P; Gatti C, Farrugia $\mathrm{L} J$, Mallinson $\mathrm{P} R$, Volkov $\mathrm{A}$, Su Z, Richter T and Hansen N K XD 2003 A computer program package for multipole refinement and analysis of electron densities from diffraction data, version 4.10; Free University of Berlin: Berlin; University of Wales: Cardiff, UK; Universita di Milano: Milano, Italy; University of Glasgow: Glasgow, UK; State University of New York: Buffalo, NY; University of Nancy: Nancy, France

37. Allen F H, Kennard O, Watson D G, Brammer L, Orpen A G and Taylor R 1987 J. Chem. Soc., Perkin Trans. II $\mathrm{S} 1$

38. Hubschle C B and Luger P 2006 J. Appl. Crystallogr. 39901

39. Ranganathan A, Kulkarni G U and Rao C N R 2003 J. Mol. Str. 656249

40. Su Z and Coppens P 1997 Acta. Crystallogr. A48 188

41. Users manual XD program version 4.10, 2003

42. Atkins P W 2002 Physical chemistry (Oxford University Press) 7 th edn

43. Abramov Y A, Volkov A V and Coppens P 1999 Chem. Phys. Lett. 31181

44. Batista E R, Xantheas S S and Jónsson H $1998 \mathrm{~J}$. Chem. Phys. 1094546

45. (a) Velde G te, Bickelhaupt F M, van Gisbergen S J A, Guerra C F, Baerends E J, Snijders J G and Ziegler T 2001 J. Comput. Chem. 22 931; (b) Guerra C F, Snijders J G, Velde G te and Baerends E J 1998 Theor. Chem. Acc. 99 391; (c) ADF2007.01, SCM, Theoretical Chemistry, Vrije Universiteit, Amsterdam, The Netherlands, http://www.scm.com

46. When we consider fragments with localized charges with total asymmetric unit being neutral, the dipole moments are relatively high, as expected. In MELT, the L-tartrate and melaminium ions have dipole moments of 23.59D and 19.42 D respectively, while in LASP, the picrate and L-asparaginium ions carry dipole moments of $11.47 \mathrm{D}$ and $20.26 \mathrm{D}$ respectively. However, these quantities can not be used in our discussion on neutral asymmetric units 